\title{
Vehicular particulate emissions in Mysore city
}

\section{AZIS KEMAL FAUZIE AND G.V. VENKATARAMANA}

Article Chronicle :

\section{Received :}

23.04.2016;

Revised :

04.05.2016;

Accepted :

19.05.2016
ABSTRACT : The study has employed a model to estimate vehicular $\mathrm{PM}_{2.5}$ and $\mathrm{PM}_{10}$ emission in urban area by calculating vehicles travel on the city roads including registered vehicles in the city and other vehicles from other cities. Data showed that about half million vehicles travel in Mysore city in 2010, and it increased by 100 thousands in 2013. Two-wheelers dominated the city roads into half of the vehicle population followed by four-wheelers and other vehicle categories. All vehicles emit more than 1.5 tonne particulates per day in 2010 for each $\mathrm{PM}_{2.5}$ and $\mathrm{PM}_{10}$ and it increased by $100 \mathrm{~kg}$ for $\mathrm{PM}_{2.5}$ and $70 \mathrm{~kg}$ for $\mathrm{PM}_{10}$ after the next three years. Nearly half of vehicular $\mathrm{PM}_{2.5}$ was emitted by heavy diesel vehicles like trucks and buses, while $\mathrm{PM}_{10}$ was generated by all vehicle types with almost the same share. Study revealed that vehicular emissions now become major threats in Mysore city.

HOW TO CITE THIS ARTICLE : Fauzie, Azis Kemal and Venkataramana, G.V. (2016). Vehicular particulate emissions in Mysore city. Asian J. Environ. Sci., 11(1): 78-86, DOI: 10.15740/HAS/AJES/11.1/78-86.

Key Words :

Outdoor air

pollution,

Particulate matter, Vehicular emission, Traffic congestion, $\mathrm{PM}_{10}$, $\mathrm{PM}_{2.5}$ 